\title{
Analysis of Ability for Understanding the Basic Concepts of Probability Theory
}

\author{
Georgina Maria Tinungki ${ }^{1, *}$ Budi Nurwahyu ${ }^{2}$ \\ 1,2 Mathematics Education Scientific Group, Faculty of Mathematics and Natural Sciences, Hasanuddin University, \\ Makassar 90245, Indonesia \\ *Corresponding author's email: georgina@unhas.ac.id
}

\begin{abstract}
This study aims to analyse the skills to understand mathematical concepts in the Probability Theory subject. As a scientific discipline, Probability Theory is one of the statistics study program subjects that require mathematical skills to learn. One of the skills needed for learning is the skill of understanding mathematical concepts. The analysis of skills in understanding mathematical concepts in the Probability Theory course shows that students still have difficulty checking the truth and writing the concepts used in each discussion of the material. This is one of the factors that make students' skills to understand mathematical concepts not good. Based on this research, it appears that students' mathematical understanding skills in the Probability Theory course are still lacking. Understanding the concept of statistics is not currently apparent in students when studying the Probability Theory. They have not been able to optimize all their mathematical abilities in learning, so they tend to give up on doing tasks when experiencing difficulties. This research is expected to be a reference and discourse for practitioners of mathematics education to improve the ability to understand the basic concepts of Probability Theory.
\end{abstract}

Keywords: Probability theory, Basic Concept, Analysis Ability, Mathematical Teaching, Statistical Teaching.

\section{INTRODUCTION}

Understanding Statistics at the tertiary level is rather difficult to learn because the material presented is more abstract. In studying statistics, students need mathematical abilities, including the ability to understand statistical concepts. Understanding statistical concepts is an activity of discovering truth or error and giving reasons for each step of an understanding process $[1,2]$.

Statistics play an important role in research, both in the preparation of models, the formulation of hypotheses, the development of data collection tools and instruments, the preparation of research designs, the determination of samples, and data analysis [1]. In many cases, the processing and analysis of data do not escape applying specific statistical techniques and methods, whose presence can provide a basis for explaining the relationships that occur [3]. Statistics can be used as a tool to find out whether the causality relationship between two or more variables is related correctly in an empirical causality or whether the relationship is just random or accidental [4].

One of the courses in the Undergraduate program in Statistics at the Department of Mathematics that requires the ability to understand statistics is Probability theory. Probability theory is one of the courses that emphasize aspects of deductive reasoning / mathematical proof. In this research, it is expected that by planting appropriate mathematical concepts, students can be the ability of the statistical concepts of Probability.

\section{LITERATURE REVIEW}

\subsection{Probability Theory}

In many cases, experiments cannot provide definitive results. Even though we make a coin several times, we cannot be sure that a certain deposit will produce a "face," and another will produce a "back" [5]. Nevertheless, we know that every experiment has an element of probability, and we know all the possibilities 
that can occur from an experiment [6]. These possibilities are called sample spaces and are denoted by $\mathrm{S}$. Each result in the sample space is called an element or sample point. If the sample space $S$, which is all the results from an experiment, has some elements, the elements or sample points can be listed and written between two allocations [7].

To find out the basic concepts of Probability Theory which includes [8] : Introduction to Opportunities, Opportunities, Sample Rooms, events, Conditional Opportunities, Independent Events, Random Variations, Discrete Random Variants, Continuous Random Variations, Probability Distribution Functions, Distribution Functions, and their properties, Expectations Random Variable, Specific Expectations, Chebyshev Inequality, Dual Random Variable Distribution, Two Random Variable Distribution, Conditional Random Variable Distribution of Other Random Variants, Two Random Variance of Each Other, Expansion of Distribution Form for 3 or More Random Variants, Special Distribution, Binomial Distribution, Geometry Distribution, Poisson Distribution, Gamma Distribution, Chi-Square Distribution, Exponential Distribution, Normal Distribution, Bivariate Normal Distribution, Random Variable Function Distribution, Sampling Theory, Random Variable Transformation, Moment Function Function, Beta Distribution, Student, and F, Distributed Statistics, Distributed Statistics $\overline{\mathrm{X}}$ and $\mathrm{nS} / \sigma^{2}$, Distribution Limit, Convergent in probability, Convergent in distribution, Limit distribution with moment generating function, Central limit theory, it requires a detailed understanding of all the material. This course is given to 3rd-semester students [9]. To study this course, calculus and statistical skills are required as a prerequisite course [10,11]. This course studies basic understandings in statistics, data presentation, statistical measures, opportunities, sampling distribution, estimation, and determining the minimum sample size in research and in-depth hypothesis testing so that you can easily understand other statistical science [12-14].

\subsection{Ability to Understand the Concept of Probability theory}

Numbers indicate the Probability for an event to determine how likely it is that an event will occur. A low probability value indicates that the likelihood of an event will occur very small. Conversely, if the probability value is high (close to 1), an event will likely occur [15].

Mathematics learning is directed at developing mathematical thinking skills, including understanding, problem-solving, reasoning, communication, mathematical correction, critical and open, and objective attitudes. In learning mathematics, students are accustomed to gaining understanding through experience of the properties possessed and those not possessed from a group of objects (abstractions) [15,16]. By observing examples and not examples, students are expected to grasp the understanding of a concept [17].

Difficulty in focusing attention or remember, which leads to poor learning outcomes. Students must express mathematical ideas from a manuscript in reading mathematical evidence, both in oral and written form, with their language. Thus, a reader does not merely recite the manuscript but expresses the meaning contained in the manuscript in question. In other words, reading statistical concepts is a set of skills to compile the essence of information from a manuscript $[4,14,18]$.

\section{METHODS}

The method used in this research is the qualitative method. The subjects in this study were students of the Statistics Study Program at a State university in Makassar who contracted the Probability Theory Course. The sampling technique used was purposive sampling, while the data collection method used was the triangulation method [19].

\section{FIGURES AND TABLES}

\subsection{Analysis of Documentation Result}

The following are given questions and test completion, and some student test answers related to the ability to read mathematical concepts in the Probability Theory course.

Test Questions (Tinungki, 2019):

The known distribution of probability for office A and office B is as follows:

Table 1. Office A (Kantor A)

\begin{tabular}{|l|l|l|l|}
\hline$x$ & 1 & 2 & 3 \\
\hline$f(x)$ & 0.3 & 0.4 & 0.3 \\
\hline
\end{tabular}

Table 2. Office B (Kantor B)

\begin{tabular}{|l|l|l|l|l|l|}
\hline$x$ & 0 & 1 & 2 & 3 & 4 \\
\hline$f(x)$ & 0.2 & 0.1 & 0.3 & 0.3 & 0.1 \\
\hline
\end{tabular}

Determine the variance of the probability distribution of offices A and B

Answer : 
Office A:

$$
\begin{aligned}
& \mu_{A}=E(X)=1(0.3)+2(0.4)+3(0.3)=2 \\
& \sigma_{A}^{2}=\sum_{x=1}^{3}(x-2)^{2} f(x)=(1-2)^{2}(0.3)+(2-2)^{2}(0.4)+(3-2)^{2}(0.3)=0.6 \\
& =(1-2)^{2}(0.3)+(2-2)^{2}(0.4)+(3-2)^{2}(0.3)=0.6
\end{aligned}
$$

\section{Office B:}

$$
\begin{aligned}
& \mu_{B}=E(X)=0(0.2)+1(0.1)+2(0.3)+3(0.3)+4(0.1)=2 \\
& \sigma_{B}^{2}=\sum_{x=1}^{3}(x-2)^{2} f(x)=4(0.2)+1(0.1)+0(0.3)+1(0.3)+4(0.1)=1.6
\end{aligned}
$$

Based on the discussion, it can be seen that the variance in the number of cars used for service is greater for office B.

The answer of student 1

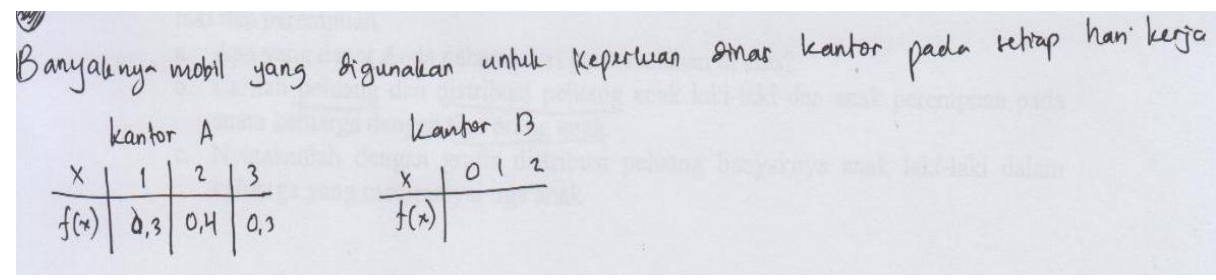

The answer of student 2

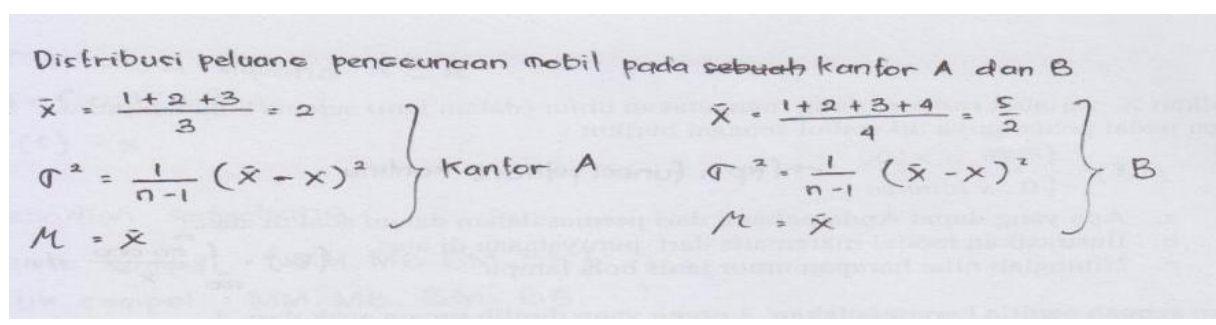

Figure 1. Answers of student 1 and student 2

The two student answers to the fourth indicator explain or interpret the results according to the original problem; it appears that the statement is incomplete, which students should explain the variance of the distribution of probability from offices A and B, namely:

Office A:

$$
\begin{aligned}
& \mu_{A}=E(X)=1(0.3)+2(0.4)+3(0.3)=2 \\
& \sigma_{A}^{2}=\sum_{x=1}^{3}(x-2)^{2} f(x)=(1-2)^{2}(0.3)+(2-2)^{2}(0.4)+(3-2)^{2}(0.3)=0.6
\end{aligned}
$$




\section{Office B:}

$$
\begin{aligned}
& \mu_{B}=E(X)=0(0.2)+1(0.1)+2(0.3)+3(0.3)+4(0.1)=2 \\
& \sigma_{B}^{2}=\sum_{x=1}^{3}(x-2)^{2} f(x)=4(0.2)+1(0.1)+0(0.3)+1(0.3)+4(0.1)=1.6
\end{aligned}
$$

So the variance in the number of cars used for service is greater for office B.

Here is another problem, which asks whether the probability distribution for the random variable is a form of the distribution function. Here are two student answers in answering questions that can explain:

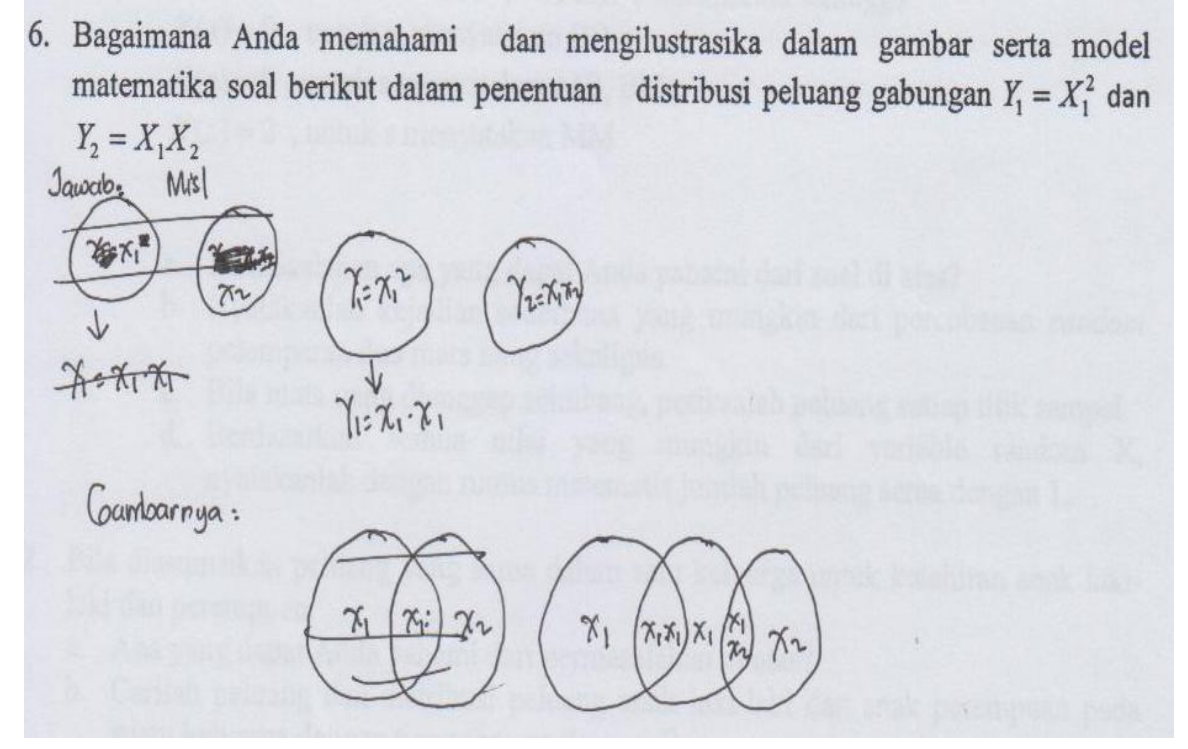

Figure 2. Student answers 3

Student 3 answer appears that the random variable probability distribution made is correct, clear, and complete, but there is a calculation error in the solution even though it leads to the correct answer, which students should explain: based on values and then the transformation 1-1. Inverse of $y_{1}=x_{1}^{2}$ is $x_{1}=\sqrt{y_{1}}$ and inverse of $y_{2}=x_{1} x_{2}$ is $x_{2}=\frac{y_{2}}{x_{1}}=\frac{y_{2}}{\sqrt{y_{1}}}$, so the Jacobian transformation $J=\left|\begin{array}{ll}\frac{d x_{1}}{d y_{1}} & \frac{d x_{1}}{d y_{2}} \\ \frac{d x_{2}}{d y_{1}} & \frac{d x_{2}}{d y_{2}}\end{array}\right|=\left|\begin{array}{cc}\frac{1}{2 \sqrt{y_{1}}} & 0 \\ -y_{2} / 2 y_{1}^{3 / 2} & \frac{1}{\sqrt{y_{1}}}\end{array}\right|=\frac{1}{2 y_{1}}$
To determine the set $\mathrm{B}$ of points on the plane $y_{1} y_{2}$ which is a map of the set $\mathrm{A}$ of points $x_{1} x_{2}$, write it down

$$
x_{1}=\sqrt{y_{1}} \quad \text { and } x_{2}=\frac{y_{2}}{\sqrt{y_{1}}}
$$

Then take it $x_{1}=0, x_{2}=0 ; x_{1}=1, x_{2}=1$, i.e. the boundaries of set A, and transform into $y_{1}=0, y_{2}=0 ; y_{1}=1, y_{2}=\sqrt{y_{1}} \quad$ or $\quad y_{2}^{2}=y_{1}$, namely the boundaries of set $\mathrm{B}$.

Here is another example of a student's answer: 


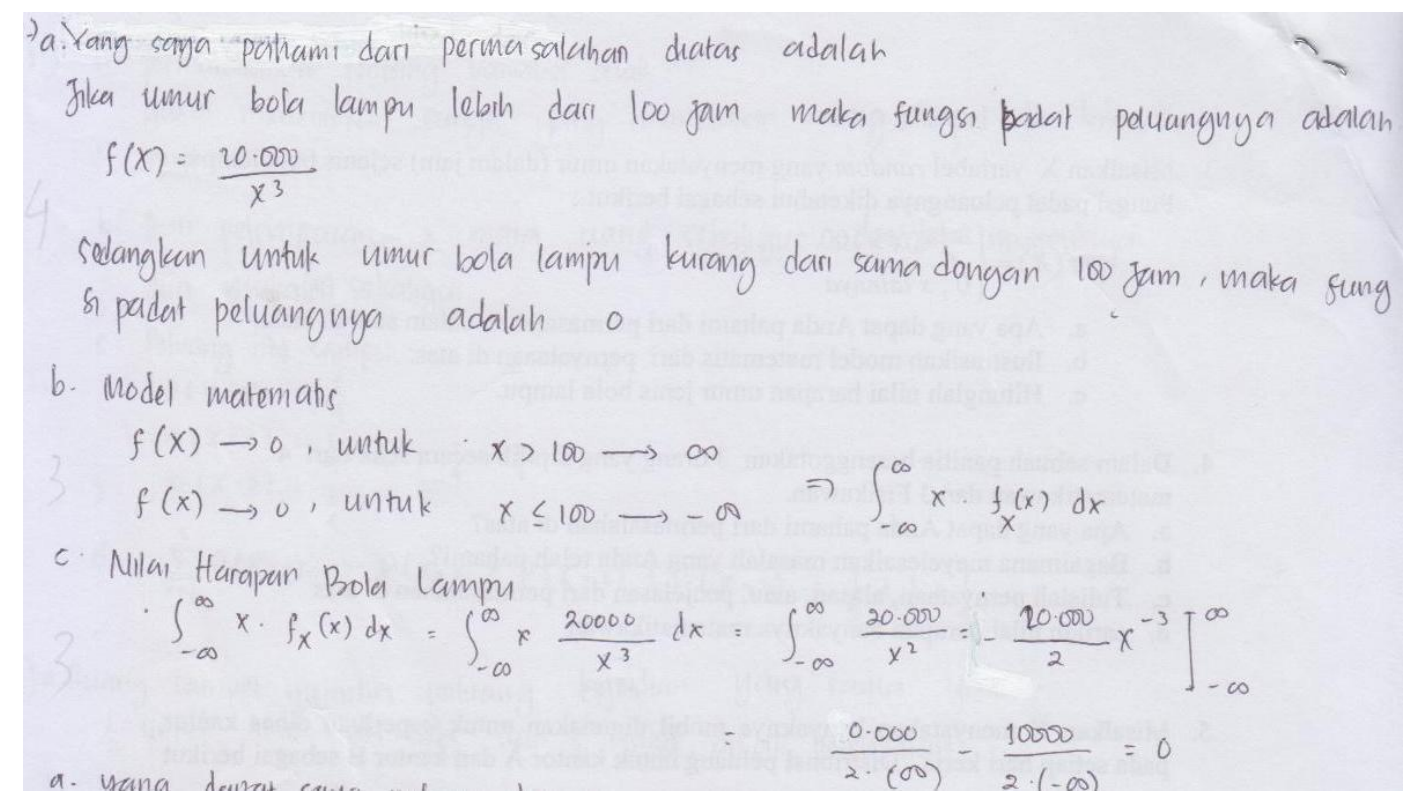

Figure 3. One of the answer of student 4

Of all the students who answered this problem, only $24 \%$ were able to answer correctly; the mistakes that often appeared when answering were students did not understand the concept problem as shown in Figure 3 above, so they were unable to plan what strategies to solve the problem and ultimately were unable to solve it problem correctly.

\subsection{Analysis of Observation and Interview Results}

Based on the results of observations and interviews with students who contracted the Probability Theory Course at a State university in Makassar City related to the ability to understand mathematical concepts, it appears that some students still have difficulty understanding the flow of problem-solving in understanding concepts, including difficulties. in checking the correctness of the concept and writing the concepts used. One of the factors causing this is the weak concept of prerequisite courses (Calculus and Basic Statistics).

For the Calculus Course, several students admitted that they were still weak in mastering the concept of partial derivatives, especially in solving problems related to more complex partial derivatives. They sometimes get confused when deriving a variable partially if the number of variables in the function is large. They are also still weak in applying derivative techniques in solving derivative problems, such as the concept of derivatives in multiplication and division of two or more functions and the concept of the chain rule in derivatives.
For Basic Statistics Subject, some students admitted that they were still weak in the concept of expectations, especially regarding moments. They are often confused between concepts by definition and postulate and students' lack of understanding of the relationship between expectation, mean, variance, and covariance.

To strengthen the analysis, the researcher also observed and interviewed one of the lecturers who taught the Probability Theory Course. Lecturers admit that the learning model used is still conventional, which emphasizes lecturers' activities in explaining the material, question, and answer, and deepening the material through working on and discussing practice questions. Lecturers also admit that some students' mastery of the prerequisite courses is still weak, so that lecturers often have to review the material. By reviewing the prerequisite material, students can better understand the Probability Theory material, which often requires the ability to understand mathematical concepts.

Based on the description above, it can be seen that the ability to understand students' mathematical concepts in the Probability Theory Course is generally still not right.

\section{CONCLUSION AND RECOMMENDATION}

The ability to understand students' mathematical concepts in the Probability Theory Course is still not good enough. This can be seen from some students who still have difficulty understanding the flow of a concept, including difficulties in checking the correct 
understanding of the concept and writing the concepts used.

Through this research, a lecturer who teaches the Probability Theory course is recommended to apply a suitable learning model to improve students' ability to understand mathematical concepts.

\section{AUTHORS' CONTRIBUTIONS}

Conceptualization: Georgina Maria Tinungki, Budi Nurwahyu

Data curation: Georgina Maria Tinungki

Formal analysis: Georgina Maria Tinungki

Funding acquisition: Georgina Maria Tinungki

Investigation: Georgina Maria Tinungki

Methodology: Georgina Maria Tinungki

Project administration: Georgina Maria Tinungki

Resources: Georgina Maria Tinungki

Software: Georgina Maria Tinungki

Supervision: Georgina Maria Tinungki, Budi Nurwahyu.

Validation: Georgina Maria Tinungki, Budi Nurwahyu

Writing - original draft: Georgina Maria Tinungki.

Writing - review \& editing: Georgina Maria Tinungki, Budi Nurwahyu.

\section{ACKNOWLEDGMENTS}

The author would like to thank the students of probability theory subject who acted as the object of observation.

\section{REFERENCES}

[1] Borovcnik M. Multiple Perspectives on the Concept of Conditional Probability. Av Investig en Educ Matemática. 2012;(2):5-27.

[2] Tinungki GM. Zone Proximal Development Gives a New Meaning To the Students' Intelligence in Statistical Method Lesson. J Honai Math. 2019;2(2):129-42.

[3] Borovenik M, Kapadia R. A Historical and Philosophical Perspective on Probability. In: Probabilistic Thinking, Advances in Mathematics Education. Dordrecht: Springer Science+ Business Media; 2014. p. 7-34.

[4] Chernoff EJ, Sriaman B. Commentary on Probabilistic Thinking: Presenting Plural Perspectives. Adv Math Educ B Ser.
2012;44(7):941-52.

[5] Ball DL, Thames MH, Phelps G. CONTENT KNOWLEDGE FOR TEACHING: WHAT MAKES IT SPECIAL? Int Encycl Educ. 2010;656-61.

[6] Franklin C, Kader G, Mewborn D, Moreno J, Peck R, Perry M, et al. Guidelines for Assessment and Instruction in Statistics Education (GAISE) Report. Alexandria: American Statistical Association Alexandria,; 2005. 1-61 p.

[7] Batanero C. Teaching and learning probability. In Encyclopedia of Mathematics Education. Heidelberg: Springer; 2013. p. 491-6.

[8] Lee HS, Angotti RL, Tarr JE. Making Comparisons Between Observed Data and Expectied Outcomes: Students' Informal Hypothesis Testing with Probability Simulation Tools. Stat Educ Res J. 2010;9(1):68-96.

[9] Batanero C. Understanding randomness: Challenges for research and teaching. In: CERME 9 - Ninth Congress of the European Society for Research in Mathematics Education, Charles University in Prague, Faculty of Education. Prague; 2016. p. 34-9.

[10] Nurwahyu B, Tinungki GM. Concept image and its influence on beliefs: Case study on undergraduate engineering students in solving of calculus concept problems. Int J Adv Sci Technol. 2020;29(5):2227-43.

[11] Nurwahyu B, Tinungki GM, Mustangin. Students' Concept Image and Its Impact on Reasoning towards the Concept of the Derivative. Eur J Educ Res. 2020;9(4):1723-34.

[12] Batanero C, Arteaga P, Serrano L, Ruiz B. Prospective Primary School Teachers' Perception of Randomness. In: Advances in Mathematics Education Series. Heidelberg: Springer; 2014. p. 345-66.

[13] Tinungki GM, Nurwahyu B. The Implementation of Google Classroom as the E-Learning Platform for Teaching Non-Parametric Statistics during COVID- 19 Pandemic in Indonesia. Int J Adv Sci Technol. 2020;29(4):5793-803.

[14] Tinungki GM. The Role of Cooperative Learning Type Team Assisted Individualization to Improve the Students' Mathematics Communication Ability in the Subject of Probability Theory. J Educ Pract [Internet]. 2015;6(32):27-31. Available from: https://eric.ed.gov/?id=EJ1083611 
[15] Purwaningsih K, Zaenuri, Hidayah I. Analysis of Concept Understanding Ability in Contextual Teaching And Learning in Quadrilateral Materials Viewed from Students Personality Type. Unnes J Math Educ. 2017;6(1):142-51.

[16] Burrill G, Biehler R. Fundamental Statistical Ideas in the School Curriculum and in Training Teachers. In: Teaching Statistics in School Mathematics-Challenges for Teaching and Teacher Education: A Joint ICMI/IASE Study. Dordrecht: Springer Science+Business Media; 2011. p. 57-69.

[17] Nilsson P. Conceptual variation and coordination in probability reasoning. J Math Behav. 2009;28(4):247-61.

[18] Chernoff EJ. Recognizing revisitation of the representativeness heuristic: An analysis of answer key attributes. ZDM - Int J Math Educ. 2012;44(7):941-52.

[19] Oliver-Hoyo M, Allen D. The Use of Triangulation Methods in Qualitative Educational Research. J Coll Sci Teach [Internet]. 2006;35(4):42-7. Available from: http://faculty.yu.edu.jo/Audeh/My Gallery/papers and documents/qualitative paper4.pdf 